\title{
Quinone methide tripterine, celastrol, induces apoptosis in human myeloma cells via NF-кB pathway
}

\author{
KEIICHI TOZAWA ${ }^{1}$, MORIHIKO SAGAWA ${ }^{2}$ and MASAHIRO KIZAKI ${ }^{2}$ \\ ${ }^{1}$ Division of Hematology, Department of Internal Medicine, Keio University School of Medicine, \\ 35 Shinanomachi, Shinjuku-ku, Tokyo 160-8582; ${ }^{2}$ Department of Hematology, Saitama Medical Center, \\ Saitama Medical University, 1981 Kamoda, Kawagoe, Saitama 350-8550, Japan
}

Received May 4, 2011; Accepted June 10, 2011

DOI: $10.3892 /$ ijo.2011.1161

\begin{abstract}
Multiple myeloma is still an incurable hematological malignancy despite the development of high-dose chemotherapy with stem cell transplantation. However, the therapeutic approach for multiple myeloma has progressed significantly in the last decade. Novel agents such as bortezomib, thalidomide and lenalidomide have been introduced in clinics as expanded treatment options and have improved the outcomes of patients with multiple myeloma. More recently, the development of novel agents with better effects and lower side-effects for the treatment of multiple myeloma has became necessary in the clinical setting. Celastrol is a quinone methide triterpene derived from the medicinal plant Tripterygium wilfordii, which has been used to treat chronic inflammatory and autoimmune diseases. It also has been reported that celastrol has potential as an anticancer agent; however, the effects of celastrol against myeloma have never been reported. It has been reported that the mechanisms of action occur via the NF- $\mathrm{KB}$ pathway. However, the effects of celastrol against multiple myeloma have never been reported. The recent clinical success of proteasome inhibitor bortezomib, which acts by inhibiting the NF- $\kappa \mathrm{B}$ activity in patients with multiple myeloma led us to investigate the effects of celastrol on myeloma cells. Here we found for the first time that celastrol induces cell cycle arrest at the G1 phase followed by apoptosis in human myeloma cell line U266 cells. In addition, we showed that celastrol induces apoptosis of myeloma cells via activation of the caspase- 3 and NF- $\kappa B$ pathways. These results suggest that celastrol would be an effective therapeutic agent in signal transduction therapy for the treatment of patients with multiple myeloma.
\end{abstract}

Correspondence to: Dr Masahiro Kizaki, Department of Hematology, Saitama Medical Center, Saitama Medical University, 1981 Kamoda, Kawagoe, Saitama 350-8550, Japan

E-mail: makizaki@saitama-med.ac.jp

Key words: celastrol, apoptosis, nuclear factor- $\kappa \mathrm{B}(\mathrm{NF}-\kappa \mathrm{B})$, multiple myeloma

\section{Introduction}

Multiple myeloma is characterized by the proliferation of malignant plasma cells and is associated with an increased level of monoclonal protein in the blood and urine. Multiple myeloma is still an incurable hematological malignancy despite the use of high-dose chemotherapy with hematopoietic stem cell transplantation (1). Although recent studies have shown that novel agents such as bortezomib, lenalidomide and thalidomide can offer important treatment options for patients with multiple myeloma and have dramatically improved outcomes for multiple myeloma patients (1-4), the development of de novo drug resistance and unexpected side-effects such as peripheral neuropathy and pulmonary complication due to the use of those agents has been reported $(5,6)$. In addition, there is still no cure, and multiple myeloma remains a fatal disease with a median survival of 4 years (7). It has been reported that the detail of molecular mechanisms that lead to multiple myeloma and its progression (8). These findings have lead to clarification of the molecular targets of this disease and may contribute to the development of new biological targeted therapies for multiple myeloma.

Celastrol (Fig. 1), also known as a quinone methide tripterine, is an active compound extracted from the root bark of the traditional Chinese medicine 'Thunder of God vine' (Tripterygium wilfordii Hook F), which has been effectively used in the treatment of autoimmune diseases, chronic inflammation and neurodegenerative diseases such as arthritis, lupus erythematosus, lateral sclerosis and Alzheimer's disease (9-11). In addition, celastrol was reported to inhibit cancer cell proliferation and induce cell death in vitro and in vivo $(12,13)$. Although celastrol has been shown to be promising in tumor prevention, the direct targets and molecular mechanisms of celastrol-induced apoptosis in cancer cells remain unknown. In this study, we investigated the effect of celastrol against myeloma cells and its molecular mechanism of action for the first time.

\section{Material and methods}

Cells and cultures. Human multiple myeloma cell line U266 was obtained from the Japan Cancer Research Resources Bank (Tokyo, Japan). Cells were maintained in RPMI-1640 culture 
medium (Sigma, St. Louis, MO) supplemented with $10 \%$ fetal bovine serum (Sigma), $100 \mathrm{U} / \mathrm{ml}$ penicillin, and $100 \mathrm{mg} / \mathrm{ml} \mathrm{strep-}$ tomycin in a humidified atmosphere with $5 \% \mathrm{CO}_{2}$. Morphology was examined on cytospin slides stained with Giemsa.

Reagents. Celastrol was purchased from Sigma and dissolved in DMSO at a stock concentration of $10 \mathrm{mM}$.

Assays for cellular viability and proliferation. Cellular viability was studied by counting the viable cells using trypan blue exclusions, and cellular proliferation was measured using CellTiter $96^{\circledR}$ AQueous One Solution cell proliferation assay (Promega, Madison, WI). For the assay, cells were plated on 96-well tissue culture plates at $5 \times 10^{4} / \mathrm{ml}$ in a total volume of $500 \mu \mathrm{l}$ with a range of concentrations of celastrol from 0.1 to $1 \mu \mathrm{M}$, and assayed according to the manufacturer's instructions. The absorbance at $490 \mathrm{~nm}$ was expressed as a relative value of the control culture.

Assays for apoptosis. Apoptosis was determined by morphological changes as well as by staining with Annexin V-FITC and propidium iodide (PI)-double labeling. The cells were treated with celastrol $(0.25$ and $0.5 \mu \mathrm{M})$ for the indicated times (0-48 h). Apoptotic cells were quantified by Annexin V-FITC and PI-double staining using a staining kit purchased from Bio Vision (Mountain View, CA). The cells were analyzed on a flow cytometer (FACSCalibur, Becton-Dickinson, San Jose, CA).

Cell cycle analysis. The celastrol-treated cells were washed twice with PBS and suspended in hypotonic solution $[0.1 \%$ Triton X-100, 1 mM Tris- $\mathrm{HCl}$ ( $\mathrm{pH} 8.0), 3.4 \mathrm{mM}$ sodium citrate, $0.1 \mathrm{mM}$ EDTA, and PI $50 \mu \mathrm{g} / \mathrm{ml}]$ and stained with $50 \mu \mathrm{g} / \mathrm{ml}$ of PI. The DNA content was analyzed by FACSCalibur. The population of cells in each cycle phase was determined using Cell ModiFIT software (Becton-Dickinson).

Assay for caspase-3 activity and mitochondrial transmembrane potential (MMP). Caspase-3 activity was determined by using a commercially available kit (caspase-3 assay kit; PharMingen, San Diego, CA) according to the manufacturer's instructions. Briefly, the cells $\left(1 \times 10^{5}\right)$ were washed twice with chilled PBS and fixed using Cytofix/Ctytoperm ${ }^{\mathrm{TM}}$ for $20 \mathrm{~min}$ on ice; the cells were then pelletted and washed in Perm/ Wash $^{\text {TM }}$ buffer (PharMingen). The cells were then stained with FITC-conjugated rabbit anti-active caspase-3 monoclonal antibody (PharMingen) for $30 \mathrm{~min}$ at room temperature, and were analyzed by flow cytometry. The mitochondrial transmembrane potential (MMP) was determined by FACSCalibur (Becton-Dickinson). The cells were washed once with PBS and incubated with $40 \mu \mathrm{M}$ DioC6 (Sigma) at $37^{\circ} \mathrm{C}$ for $20 \mathrm{~min}$. DioC6 intensity was determined by flow cytometry.

$N F-\kappa B$ transcription factor assay. The cells were pre-treated with $0.5 \mu \mathrm{M}$ of celastrol for 3, 6 and $12 \mathrm{~h}$, and collected by centrifugation at $500 \mathrm{x}$ g for $5 \mathrm{~min}$. The pellets were resuspended in a lysis buffer [1\% NP40, $1 \mathrm{mM}$ phenylmethylsulfonyl fluoride (MPSF), $40 \mathrm{mM}$ Tris- $\mathrm{HCl}$ (pH 8.0), $150 \mathrm{mM} \mathrm{NaCl}$, $1 \mathrm{mM} \mathrm{NaOV}]$ at $4^{\circ} \mathrm{C}$ for $15 \mathrm{~min}$. The level of NF- $\kappa \mathrm{B}$ was assessed by ELISA using monoclonal antibodies and the procedure

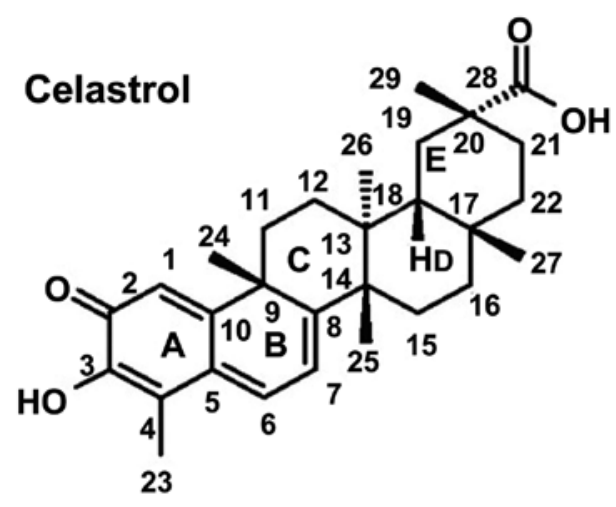

Figure 1. Chemical structure of celastrol.

recommended by the manufacturer (TransAM NF- $\mathrm{B}$ p65 transcription factor assay kits; Active Motif, Carlsbad, CA).

Cell lysate preparation and Western blotting. Cells were collected by centrifugation at $700 \mathrm{x}$ g for $10 \mathrm{~min}$ and then the pellets were resuspended in lysis buffer [1\% NP-40, $1 \mathrm{mM}$ phenylmethylsulfonyl fluoride (PMSF), $40 \mathrm{mM}$ Tris- $\mathrm{HCl}$ (pH 8.0), $150 \mathrm{mM} \mathrm{NaCl}]$ at $4^{\circ} \mathrm{C}$ for $15 \mathrm{~min}$. Protein concentrations were determined using a protein assay DC system (Bio-Rad, Richmond, CA). Cell lysates (15 $\mu \mathrm{g}$ protein per lane) were fractionated in $12.5 \%$ SDS-polyacrylamide gels prior to transfer to the membranes (Immobilon-P membranes; Millipore, Bedford, MA) using a standard protocol. Antibody binding was detected using an enhanced chemiluminescence kit for Western blotting detection with hyper-ECL film (Amersham, Buckinghamshire, UK). Blots were stained with Coomassie brilliant blue to confirm that there were equal amounts of protein extract on each lane. The following antibodies were used in this study: NF- $\kappa$ B p65 and I $\mathrm{B}-\alpha$ purchased from Cell Signaling Technology (Beverly, MA), and Oct-1 (C-21) and $\beta$-actin (I-19) from Santa Cruz Biotechnology (Santa Cruz, CA).

Statistical analysis. Results are expressed as mean \pm standard deviation (SD). Student's t-test was used to compare quantitative data population with normal distribution and equal variance. $\mathrm{P}<0.05$ was considered statistically significant otherwise specified.

\section{Results}

Induction of apoptosis by celastrol in myeloma cells. We first examined the effects of celastrol on the cellular proliferation of human multiple myeloma cell line U266. Celastrol inhibited the cellular proliferation of myeloma cells in a dose-dependent manner with $\mathrm{IC}_{50}$ values of $0.47 \mu \mathrm{M}$ at $24 \mathrm{~h}$ (Fig. 2A). To investigate the mechanisms of celastrol-induced apoptosis of myeloma cells, we next examined the morphological changes of myeloma cells. There was a typical morphological appearance of apoptosis in U266 cells exposed to celastrol, including condensed chromatin and fragmented nuclei with apoptotic bodies (Fig. 2B). At the same time, we measured the apoptosis using Annexin-V and PI-double staining. U266 cells cultured 
A

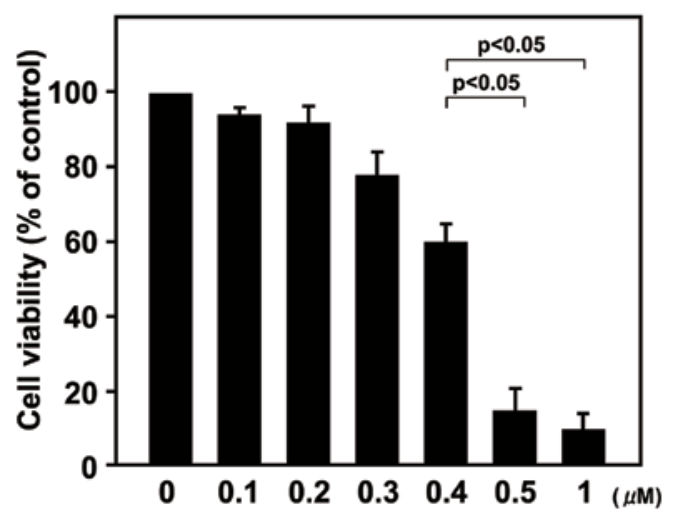

B
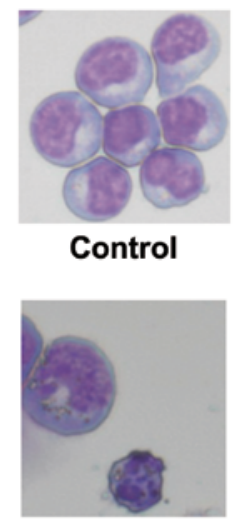

Celastrol

(0.5 $\mu \mathrm{M}, 24 \mathrm{~h})$

C
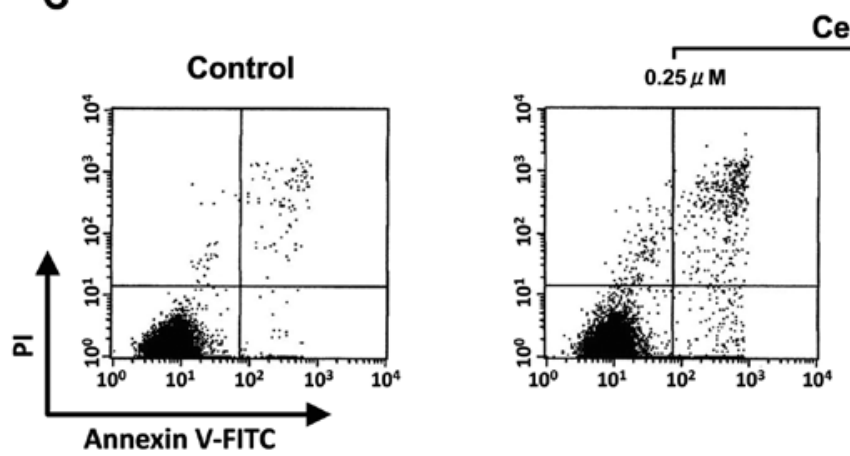

Celastrol
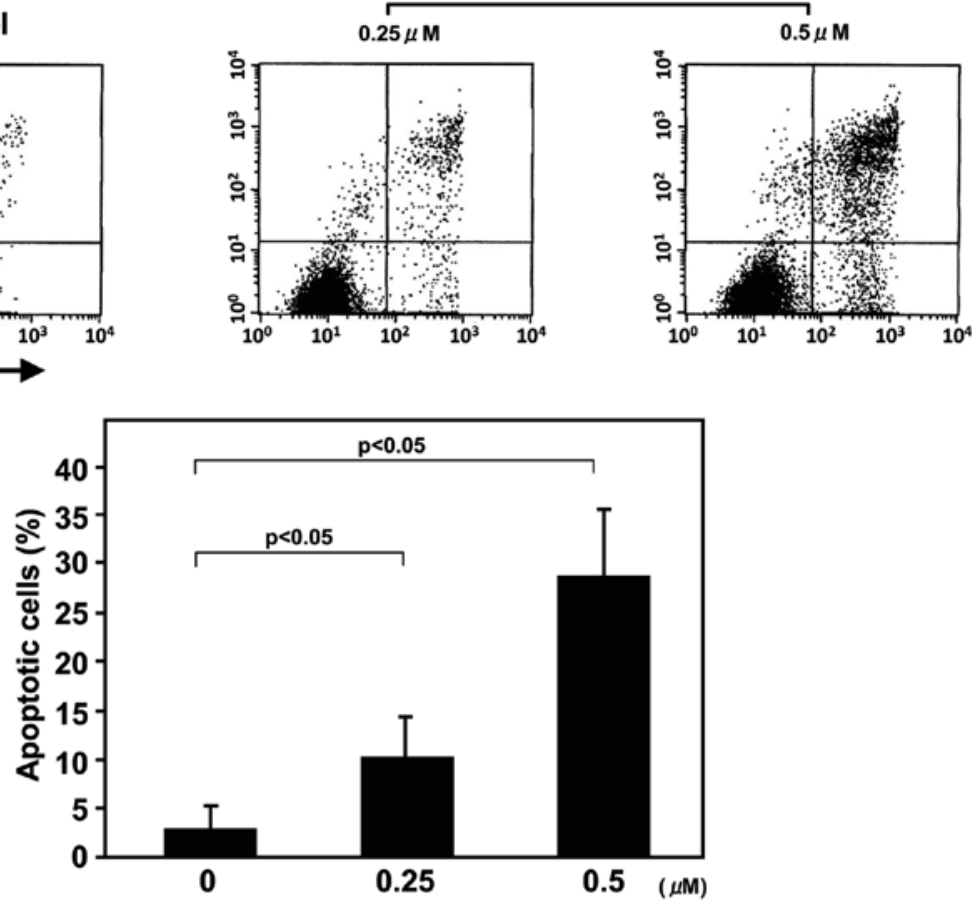

Figure 2. Growth inhibition of U266 myeloma cells by celastrol. (A) U266 cells were treated with various concentrations $(0-1 \mu \mathrm{M})$ of celastrol for 24 h. Growth inhibition was assessed by MTS growth inhibition assay. Results are expressed as the mean \pm SD of three different experiments. The IC ${ }_{50}$ value at $24 \mathrm{~h}$ is $0.47 \mu \mathrm{M}$. (B) Morphologic changes characteristic of apoptosis in U266 cells. Cells were treated with $0.5 \mu \mathrm{M}$ celastrol for $24 \mathrm{~h}$, and cytospin slides were then prepared and stained with Giemsa. Original magnification, x1000. (C) Induction of apoptosis was examined by annexin V/PI-double staining using flow cytometry analysis (upper panel). U266 cells were treated with celastrol $(0-0.5 \mu \mathrm{M})$ for $24 \mathrm{~h}$, and representative of three duplicate experiments is shown. The percentage of apoptotic cells is expressed in the histogram as mean $\pm \mathrm{SD}$. P-value showed statistical significance.

with 0.25 and $0.5 \mu \mathrm{M}$ of celastrol for 24 and $48 \mathrm{~h}$ were stained with Annexin-V to detect externalization of phosphatidylserine on the cell membrane (Fig. 2C). Celastrol was found to induce apoptosis of U266 cells in a dose- and time-dependent manner.

Celastrol induced G1 cell-cycle arrest in myeloma cells. To investigate the effect of celastrol on the cell cycle progression of myeloma cells, we analyzed the cell cycle distribution of $\mathrm{U} 266$ treated with $0.5 \mu \mathrm{M}$ of celastrol for 6,12 and $24 \mathrm{~h}$ using flow cytometry. There was an increase in the cells in the G1 phase (Fig. 3), which suggested that celastrol induced G1-phase arrest followed by apoptosis in U266 cells.
Celastrol-induced apoptosis is mediated through the caspase-3 pathway. Caspase-3 is known to be a crucial mediator of apoptosis, catalyzing the specific cleavage of many key cellular proteins. Therefore, we investigated the activity of caspase- 3 in $\mathrm{U} 266$ cells treated with $0.5 \mu \mathrm{M}$ of celastrol for 9, 24 and $48 \mathrm{~h}$. The activity of caspase- 3 increased in a time-dependent manner (Fig. 4A), suggesting that the caspase-3 pathway plays an essential role in celastrol-induced apoptosis in myeloma cells.

Celastrol-induced apoptosis is mediated through the mitochondrial pathway. We examined the MMP by flow cytometry using DioC6 to address the apoptotic pathway through the mitochondria. After treatment with $0.5 \mu \mathrm{M}$ celastrol for the 

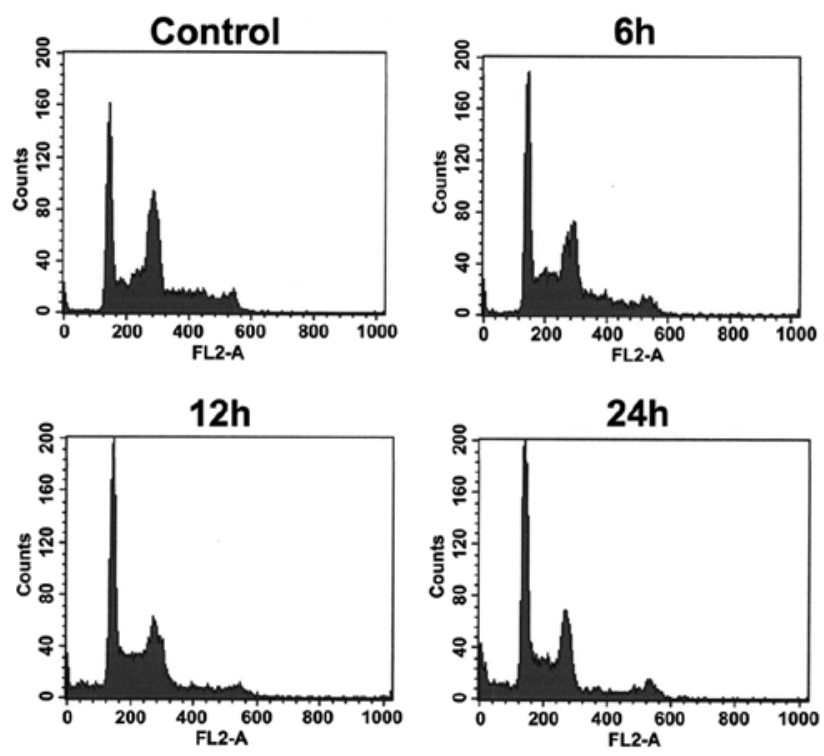

Figure 3. Celastrol-induced G1 cell cycle arrest. U266 cells were treated with $0.5 \mu \mathrm{M}$ celastrol for the indicated times and then stained with PI as described in Materials and methods. The DNA content was analyzed by means of flow cytometry.

indicated time, DioC6 staining of myeloma cells indicated an increase in the loss of MMP (Fig. 4B). These results suggest that celastrol-induced apoptosis is mediated through a mitochondria-dependent pathway.

$N F-\kappa B$ pathway is crucial in celastrol-induced apoptosis. The $\mathrm{NF}-\kappa \mathrm{B}$ pathway is a key regulator of cytokine stimulation, the cell cycle, apoptosis and angiogenesis $(14,15)$. It is also critical in the progression and apoptosis of cancer cells, including multiple myeloma. Recently, inhibition of the NF- $\kappa$ B pathway using the proteasome inhibitor bortezomib was found to be pivotal in the treatment of untreated and relapse/refractory

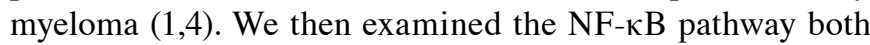
by the ELISA method and Western blotting. The expression of NF- $\kappa \mathrm{B}$ in the nucleus increased after TNF- $\alpha$ stimulation (Fig. 5A); however, as shown by ELISA, celastrol inhibited the migration of NF- $\kappa \mathrm{B}$ into the nucleus in U266 cells (Fig. 5A). It was also shown by Western blotting that the expression of $\mathrm{NF}-\kappa \mathrm{B}$ in the nucleus increased after TNF- $\alpha$ stimulation; however, celastrol inhibited the migration of $\mathrm{NF}-\kappa \mathrm{B}$ into the nucleus as well as I $\mathrm{B}$ - $\alpha$ cleavage in a time-dependent manner (Fig. 5B). These results indicated that celastrol inhibited the $\mathrm{NF}-\kappa \mathrm{B}$ pathway via the inhibition of the migration of $\mathrm{NF}-\kappa \mathrm{B}$ into the nucleus.

\section{Discussion}

Multiple myeloma is characterized by the accumulation of secretary plasma cells with a low proliferative index and an extended life span in the bone marrow. Conventional therapy for multiple myeloma involves combinations of vincristine, melphalan, cyclophosphamide, doxorubicin and prednisone or dexamethasone (16). Patients younger than 65 years are usually given high-dose melphalan with autologous stem cell support, and older patients or those who cannot tolerate such intensive treatment are given standard-dose oral melphalan and dexamethasone. However, these treatments are associated with low remission rates, short survival times and the development of drug resistance (17). Recently, novel agents such as bortezomib, thalidomide and lenalidomide, which target myeloma cells and their microenvironments, have shown remarkable activity against refractory

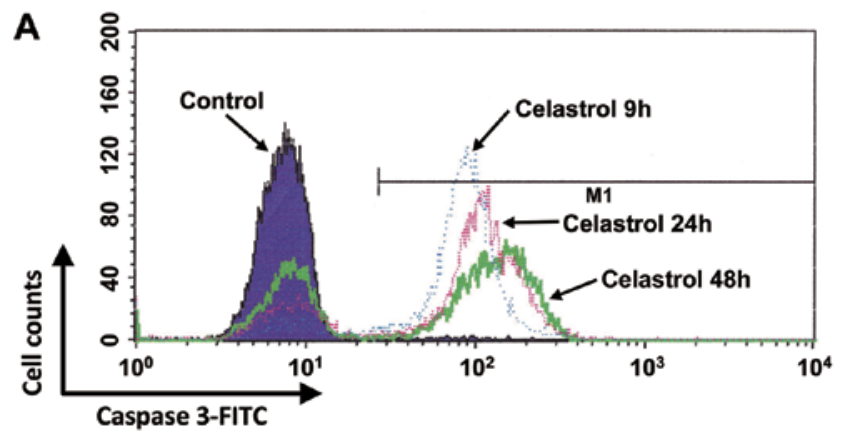

B

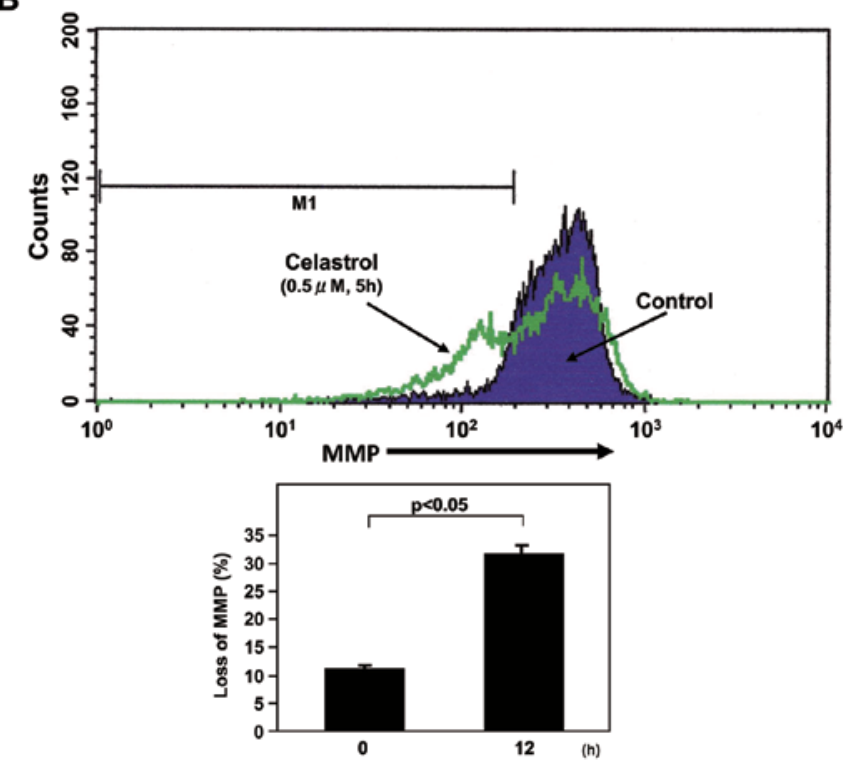

Figure 4. Celastrol-induced caspase-3 activity and loss of mitochondrial membrane potential (MMP). (A) Effect of celastrol on caspase-3 activity. Cell were incubated with $0.5 \mu \mathrm{M}$ celastrol for various lengths of times (0-48 h) and then analyzed by flow cytometry and colorimetric assay (upper panel). Caspaseactivated cells were expressed as a histogram (lower panel). (B) Flow cytometric analysis of MMP as estimated by Rh123 intensity (upper panel) and expressed as a histogram (lower panel). U266 cells were cultured with $0.5 \mu \mathrm{M}$ celastrol for $12 \mathrm{~h}$, and Rh123 fluorescence was analyzed by flow cytometry. P-values show statistical significance. 

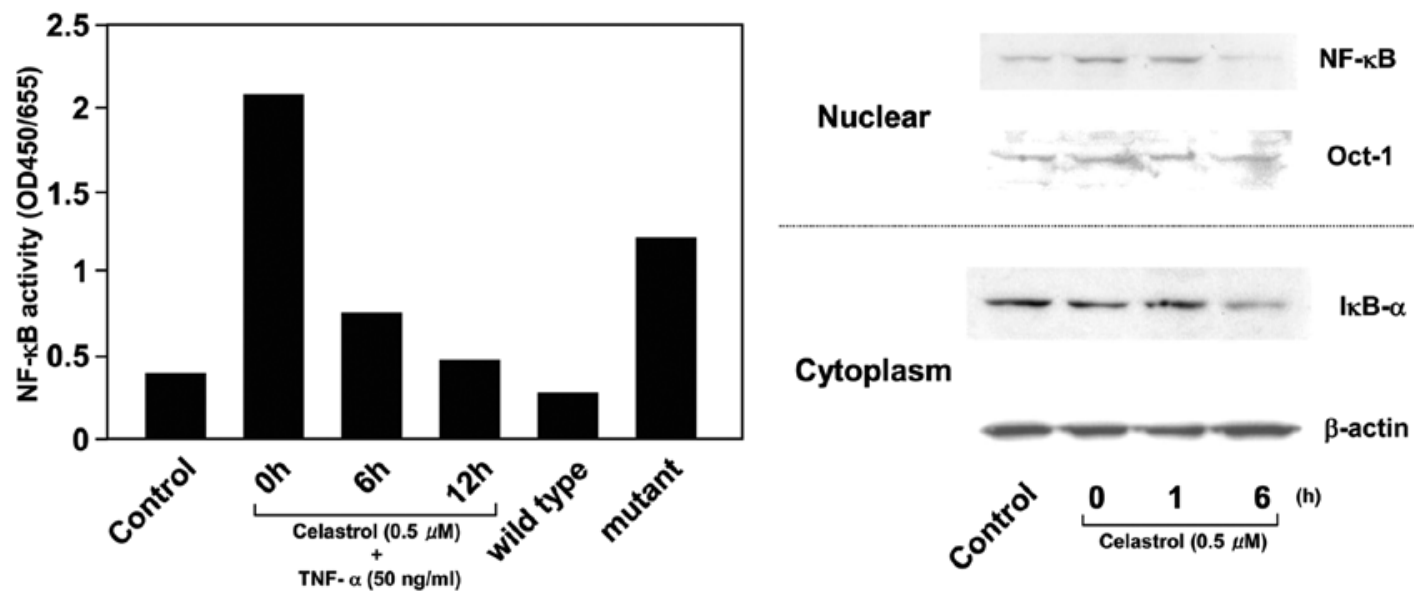

Figure 5. Effects of celastrol on NF- $\mathrm{BB}$ activity in myeloma cells. (A) U266 cells were treated with $50 \mathrm{ng} / \mathrm{ml} \mathrm{TNF}-\alpha$ for $12 \mathrm{~h}$, and then the cells were incubated with $0.5 \mu \mathrm{M}$ of celastrol for 6 and $12 \mathrm{~h}$. The DNA binding activity of NF- $\kappa \mathrm{B}$ in U266 cells was quantified by ELISA with the use of a Trans-AM NF- $\kappa \mathrm{B}$ p65 transcription factor assay kit. Celastrol significantly suppressed the stimulatory effect of TNF- $\alpha$ on NF- $\kappa \mathrm{B}$ DNA binding activity (P<0.01). The control is referred to as no stimulated control, the wild-type as wild-type oligonucleotide, and the mutant as mutant oligonucleotide. (B) Effects of celastrol on the

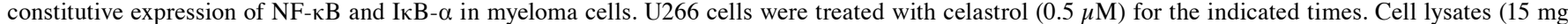
protein per lane) were fractionated in $12.5 \%$ SDS-polyacrylamide gels and analyzed by Western blotting with an antibody against NF- $\kappa \mathrm{B}$ p 65 and $\mathrm{I} \kappa \mathrm{B}-\alpha$. Nuclear and cytoplasmic extracts were prepared in order to check these proteins by Western blotting.

and chemoresistant cases in early clinical trials, and they have prolonged the progression-free and overall survival of multiple myeloma patients $(18,19)$. Progression and chemoresistance are thought to involve interleukin (IL)-6, the expression of which is induced by $\mathrm{NF}-\kappa \mathrm{B}$, via its regulation of the growth and survival of myeloma cells (1). IL-6 leads to the constitutive activation of STAT3, which in turn results in the expression of high levels of anti-apoptotic Bcl-xL and Mcl-1 proteins $(20,21)$. Thus, the constitutive activation of both $\mathrm{NF}-\kappa \mathrm{B}$ and STAT3 plays an important role in chemoresistance, and it is expected that the inhibition of NF- $\kappa$ B and STAT3 may overcome such chemoresistance. However, many patients have relapsed and have been refractory to each agent. Therefore, novel therapeutic agents that can overcome drug resistance are required.

Many natural products have been developed as anticancer agents in clinical settings (22). For the past 30 years, many natural products have provided lead structures, and these have been used as templates for developing new agents with enhanced biological properties (23). Such new agents are mostly derived from plants and marine products with less toxicity than chemotherapeutic agents. We have previously reported that many natural products induced apoptosis of human leukemia and myeloma cells through the basic molecular mechanisms that take place in these cells (24-30).

Celastrol, also known as a tripterine from Chinese traditional medicine, is an active compound extracted from the root bark of Tripterygium wilfordii Hook $F$. It has been used in the treatment of autoimmune disease, chronic inflammation and neurodegenerative diseases (9-11). Recent studies have shown that celastrol inhibits the proliferation of prostate cancer and leukemia $(12,13)$. However, there have been no reports of celastrol inducing myeloma cell death. In this study, we showed for the first time that celastrol induced apoptosis in myeloma cells through NF- $\kappa \mathrm{B}$ inhibition.

We first demonstrated in this study that celastrol inhibited the growth of human myeloma cell line U266 cells via the induction of apoptosis with an $\mathrm{IC}_{50}$ of $<5 \mu \mathrm{M}$. In addition, celastrol induced G1 cell cycle arrest. It is already known that celastrol induces cell cycle arrest at the G1 phase followed by apoptosis in various cancer cells $(31,32)$. The NF- $\kappa \mathrm{B}$ pathway is a potential molecular target for cancer therapy (33). Many cancer cells contain aberrantly sustained nuclear $\mathrm{NF}-\kappa \mathrm{B}$ activity because of aberrant IKK activity, a shorter half-life of $\mathrm{I} \kappa \mathrm{B}-\alpha$, mutation of I $\mathrm{B}-\alpha$, overexpression of IL- $1 \beta$, and excess production of TNF- $\alpha$. Several drugs that inhibit NF- $\kappa$ B activation, such as inhibitors of the upstream kinase IKK $\beta$, have already shown anti-myeloma activity in preclinical models $(33,34)$. Moreover, proteasome inhibitor bortezomib, which inhibits $\mathrm{NF}-\kappa \mathrm{B}$ activation, has been widely been used to treat multiple myeloma patients worldwide $(1,4)$. Therefore, natural products that inhibit $\mathrm{NF}-\kappa \mathrm{B}$ activation could be novel potential agents for the treatment of multiple myeloma. In this study, we demonstrated that celastrol inhibited the shuttling of NF- $\kappa \mathrm{B}$ into the nucleus, which was followed by apoptosis.

Recently, celastrol has been found to be a novel Hsp90 inhibitor $(35,36)$. However, no study has found that the celastrol-induced apoptosis of myeloma cells was induced by Hsp90 inhibition. Further studies are needed to address the effect of celastrol on the inhibition of Hsp90 activity in myeloma cells.

In conclusion, we showed that celastrol induced apoptosis in myeloma cells, and that its main molecular mechanisms is the inhibition of NF- $\kappa \mathrm{B}$ activation. This drug could be a novel molecular-targeted therapy for the treatment of multiple myeloma.

\section{Acknowledgements}

We would like to thank Chika Nakabayashi for her excellent technical assistance. This study was supported by grants from the Ministry of Education, Culture, Sports, Science and Technology of Japan; and the Ministry of Health, Labor and Welfare of Japan. 


\section{References}

1. Hideshima T and Anderson KC: Molecular mechanisms of novel therapeutic approaches for multiple myeloma. Nat Rev Cancer 2: 927-937, 2002

2. Weber D: Thalidomide and its derivatives: new promise for multiple myeloma. Cancer Control 10: 375-383, 2003.

3. Laubach JP, Mahindra A, Richardson PG, et al: The use of novel agents in the treatment of relapsed and refractory multiple myeloma. Leukemia 23: 2222-2232, 2009.

4. Chauhan D, Hideshima T, Mitsiades C, Richardson P and Anderson KC: Proteasome inhibitor therapy in multiple myeloma. Mol Cancer Ther 4: 686-692, 2005.

5. Miyakoshi S, Kami M, Oshimi K, et al: Severe pulmonary complications in Japanese patients after bortezomib treatment for refractory multiple myeloma. Blood 107: 3492-3494, 2006.

6. Park SB, Krishnan AV, Lin CS, Goldstein D, Friedlander M and Kiernan MC: Mechanisms underlying chemotherapy-induced neurotoxicity and the potential for neuroprotective strategies. Curr Med Chem 15: 3081-3094, 2008.

7. Anderson KC: Targeted therapy of multiple myeloma based upon tumor-microenvironmental interactions. Exp Hematol 35 (Suppl 1): S155-S162, 2007.

8. Chanan-Khan AA, Borrello I, Lee KP and Deece DE: Development of target-specific treatments in multiple myeloma. Br J Haematol 151: 3-15, 2010.

9. Jin HZ, Hwang BY, Kim HS, Lee JH, Kim YH and Lee JJ: Antiinflammatory constituents of Celastrus orbiculatus inhibit the NF- $\kappa \mathrm{B}$ activation and NO production. J Nat Prod 65: 89-91, 2002.

10. Pinna GF, Fiorucci M, Reimund JM, Taquet N, Arondel Y and Muller CD: Celastrol inhibits pro-inflammatory cytokine secretion in Crohn's disease biopsies. Biochem Biophys Res Commun 322: 778-786, 2004.

11. Allison AC, Cacabelos R, Lombardi VR, Alvarez XA and Vigo C: Celastrol, a potent antioxidant and anti-inflammatory drug, as a possible treatment for Alzheimer's disease. Prog Neuropsychopharmacol Biol Psychiatry 25: 1341-1357, 2001.

12. Nagase M, Oto J, Sugiyama S, Yube K, Takaishi Y and Sakato N: Apoptosis induction in HL-60 cells and inhibition of topoisomerase II by triterpene celastrol. Biosci Biotechnol Biochem 67: 1883-1887, 2003.

13. Yang H, Chen D, Cui QC, Yuan X and Dou QP: Celastrol, a triterpene extracted from the Chinese 'Thunder of God Vine', is a potent proteasome inhibitor and suppresses human prostate cancer growth in nude mice. Cancer Res 66: 4758-4765, 2006.

14. Baldwin AS Jr: The NF- $\kappa \mathrm{B}$ and I $\kappa \mathrm{B}$ proteins: new discoveries and insights. Annu Rev Immunol 14: 649-683, 1996.

15. Ghost S, Mary MJ and Kopp EB: NF- $\kappa B$ and Rel proteins: evolutionarily conserved mediators of immune responses. Annu Rev Immunol 16: 225-260, 1998.

16. Palumbo A and Rajkumar SV: Multiple myeloma: chemotherapy or transplantation in the era of new drugs. Eur J Haematol 84 379-390, 2010

17. Kumar SK, Rajkumar SV, Dispenzieri A, et al: Improved survival in multiple myeloma and the impact of novel therapies. Blood 111: 2516-2520, 2008.

18. Ludwig H, Beksac M, Blade J, et al: Current multiple myeloma treatment strategies with novel agents: a European perspective. Oncologist 15: 6-25, 2010.
19. Chanan-Khan AA and Giralt S: Importance of achieving a complete response in multiple myeloma, and the impact of novel agents. J Clin Oncol 28: 1-13, 2010.

20. Catlett-Falcone R, Landowski TH, Oshiro MM, et al: Constitutive activation of Stat 3 signaling confers resistance to apoptosis in human U266 myeloma cells. Immunity 10: 105-115, 1999.

21. Zhang B, Potyagaylo V and Fenton RG: IL-6-independent expression of Mcl-1 in human multiple myeloma. Oncogene 22: $1848-1859,2003$.

22. Mann J: Natural products in cancer chemotherapy: past, present and future. Nat Rev Cancer 2: 143-148, 2002.

23. Simmons TL, Andrianasolo E, McPhail K, Flatt $P$ and Gerwick WH: Marine natural products as anticancer drugs. Mol Cancer Ther 4: 333-342, 2005.

24. Ito K, Nakazato T, Kizaki M, et al: 1'-acetoxychavicol acetate is a novel nuclear factor kappa B inhibitor with significant activity against multiple myeloma in vitro and in vivo. Cancer Res 65: 4417-4424, 2005.

25. Nakazato T, Ito K, Kizaki M, et al: Catechin, a green tea component, rapidly induces apoptosis of myeloid leukemic cells via modulation of reactive oxygen species production in vitro and inhibits tumor growth in vivo. Haematologica 90: 317-325, 2005.

26. Nakazato T, Ito K, Ikeda Y and Kizaki M: Green tea component, catechin, induces apoptosis of human malignant B cells via production of reactive oxygen species. Clin Cancer Res 11: 6040-6049, 2005.

27. Shimizu T, Nakazato T, Xian MJ, Sagawa M, Ikeda Y and Kizaki M: Resveratrol induces apoptosis of human malignant B cells by activation of caspase- 3 and p38 MAP kinase pathways. Biochem Pharmacol 71: 742-750, 2006.

28. Xian M, Ito K, Kizaki M, et al: Zerumbone, a bioactive sesquiterpene, induces G2/M cell cycle arrest and apoptosis in leukemia cells via a Fas- and mitochondria-mediated pathway. Cancer Sci 98: 118-126, 2007.

29. Muto A, Hori M, Yoshida T, et al: Emodin has a cytotoxic activity against human multiple myeloma as a Janus-activated kinase 2 inhibitor. Mol Cancer Ther 6: 987-994, 2007.

30. Sagawa M, Nakazato T, Uchida H, Ikeda $Y$ and Kizaki M: Cantharidin induces apoptosis of human multiple myeloma cells via inhibition of the JAK/STAT pathway. Cancer Sci 99: 1820-1826, 2008.

31. Lu Z, Jin Y, Qiu L, Lai Y and Pan J: Celastrol, a novel HSP90 inhibitor, depletes Bcr-Abl and induces apoptosis in imatinibresistant chronic myelogenous leukemia cells harboring T315I mutation. Cancer Lett 290: 182-191, 2010.

32. Sung B, Park B, Yadav VR and Aggarwal BB: Celastrol, a triterpene, enhances TRAIL-induced apoptosis through the downregulation of cell survival proteins and upregulation of death receptors. J Biol Chem 285: 11498-11507, 2010.

33. Garg A and Aggarwal BB: Nuclear transcription factor- $\kappa$ B as a target for cancer drug development. Leukemia 16: 1053-1068, 2002.

34. Lee CH, Jeon YT, Kim SH and Song YS: NF- $\kappa$ B as a potential molecular target for cancer therapy. Biofactors 29: 19-35, 2007.

35. Chadli A, Felts SJ, Mer G, et al: Celastrol inhibits Hsp90 chaperoning of steroid receptors by inducing fibrillization of the Co-chaperone p23. J Biol Chem 285: 4224-4231, 2010.

36. Zhang T, Li Y, Yu Y, Zou P, Jiang Y and Sun D: Characterization of celastrol to inhibit hsp90 and cdc37 interaction. J Biol Chem 284: 35381-35389, 2009 